\title{
PULL-OUT RESISTANCE OF POST-INSTALLED ANCHORS WITH CRACKS REPAIRED BY EPOXY RESIN
}

\author{
Noritaka Morohashi ${ }^{1}$ \\ 1 1-2-1, Izumicho Narashino-shi Chiba 275-8575, JAPAN, \\ morohashi.noritaka@nihon-u.ac.jp, Prof., Dept. of Architecture and Architectural \\ Engineering, College of Industrial Technology, Nihon University, Dr.Eng.
}

\begin{abstract}
In recent years, the effectiveness of repairing by injecting epoxy resin in cracks has been shown for buildings with a reinforced concrete structure that are cracked. In this study, we examined how the pull-out resistance improves when installing postinstalled anchors after repairing cracks with epoxy resin on cracked concrete base material. Results indicate that, compared to the tests specimens without cracks, the test specimens which were cracked and were not repaired, tended to have a reduced pullout resistance. On the other hand, for test specimens with cracks repaired by epoxy resin, compared to test specimens with small cracks, test specimens with large cracks were found to have an increased pull-out resistance, and in some cases, they were also found to have even an increased pull-out resistance compared to test specimens without cracks.
\end{abstract}

Keywords: Post-installed anchors, Crack repaired, Penetrating epoxy resin, Crack width

\section{INTRODUCTION}

In Japan, one of the world's most seismic nations, buildings get damaged by earthquakes. Cracks are one form of damage. The effectiveness of repairing by injecting epoxy resin in cracks has been shown for buildings with a reinforced concrete structure damaged by cracks. Moreover, when performing seismic retrofitting, postinstalled anchors may be used in the future for buildings with repaired cracks. When doing so, the post-installed anchors installed in the presence of cracks are reported to have a decreased pull-out resistance, compared to sound concrete.

In this study, we aimed to confirm how the pull-out resistance improves when installing post-installed anchors after repairing cracks on cracked concrete base material.

\section{EXPERIMENTAL}




\subsection{Test specimen overview and experimental procedure}

The flow from making the test specimens to performing the pull-out test is shown in Figure 1, and the list of test specimens is shown in Table 1.

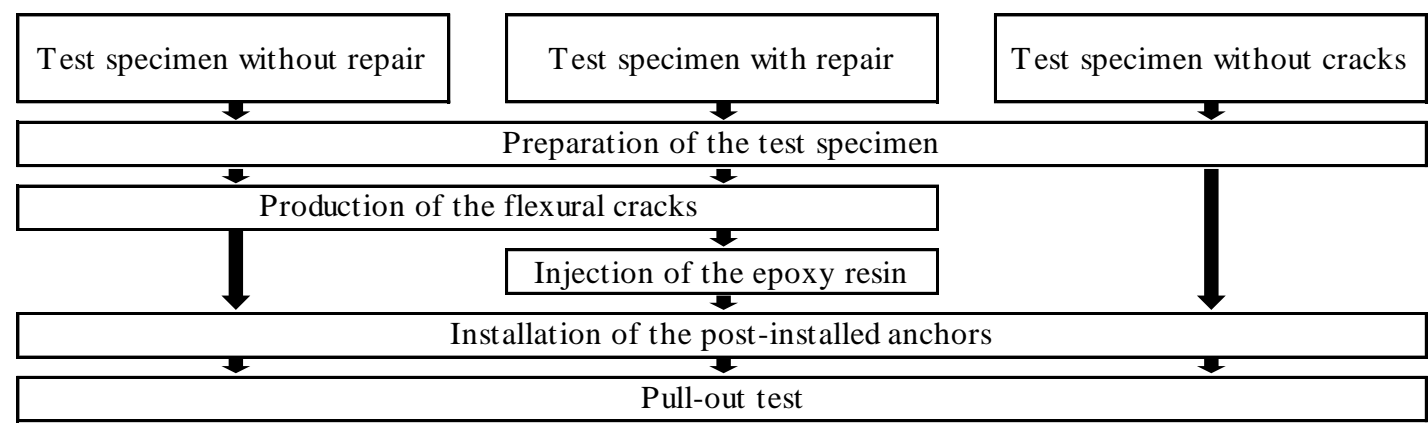

Figure 1. Flow from making the test specimens to performing the pull-out test

Table 1. List of test specimens

\begin{tabular}{|c|c|c|c|c|c|c|c|}
\hline No. & $\begin{array}{c}\text { Flexural } \\
\text { crack }\end{array}$ & $\begin{array}{c}\text { Repair by epoxy } \\
\text { resin }\end{array}$ & $\begin{array}{c}\text { Flexural crack on } \\
\text { the anchor } \\
\text { installed part } \\
\end{array}$ & \multicolumn{4}{|c|}{$\begin{array}{c}\text { Effective embedding } \\
\text { length } \\
(\mathrm{mm})\end{array}$} \\
\hline 1 & Yes & Yes & Small & 80 & ( & $5 \mathrm{da}$ & ) \\
\hline 2 & Yes & Yes & Large & 80 & ( & $5 \mathrm{da}$ & ) \\
\hline 3 & Yes & Yes & Small & 112 & ( & $7 \mathrm{da}$ & ) \\
\hline 4 & Yes & Yes & Large & 112 & ( & $7 \mathrm{da}$ & ) \\
\hline 5 & Yes & Yes & Small & 144 & ( & $9 \mathrm{da}$ & ) \\
\hline 6 & Yes & Yes & Large & 144 & ( & $9 \mathrm{da}$ & ) \\
\hline 7 & Yes & No & Small & 80 & ( & $5 \mathrm{da}$ & ) \\
\hline 8 & Yes & No & Large & 80 & ( & $5 \mathrm{da}$ & ) \\
\hline 9 & Yes & No & Small & 112 & ( & $7 \mathrm{da}$ & ) \\
\hline 10 & Yes & No & Large & 112 & ( & $7 \mathrm{da}$ & ) \\
\hline 11 & Yes & No & Small & 144 & ( & $9 \mathrm{da}$ & ) \\
\hline 12 & Yes & No & Large & 144 & ( & $9 \mathrm{da}$ & ) \\
\hline 13 & No & - & - & 80 & ( & $5 \mathrm{da}$ & ) \\
\hline 14 & No & - & - & 112 & ( & $7 \mathrm{da}$ & ) \\
\hline 15 & No & - & - & 144 & ( & $9 \mathrm{da}$ & ) \\
\hline 16 & Yes & Yes & Small & 112 & ( & $7 \mathrm{da}$ & ) \\
\hline 17 & Yes & Yes & Large & 112 & ( & $7 \mathrm{da}$ & ) \\
\hline 18 & Yes & No & Small & 112 & ( & $7 \mathrm{da}$ & ) \\
\hline 19 & Yes & No & Large & 112 & ( & $7 \mathrm{da}$ & ) \\
\hline 20 & No & - & - & 112 & ( & $7 \mathrm{da}$ & ) \\
\hline
\end{tabular}

Anchor bar diameter: M16 


\subsection{Shape of the Test Specimens}

The shape of the test specimens is shown in Figure 2. The test specimens were rectangular parallelepipeds of $440 \mathrm{~mm}$ x $500 \mathrm{~mm}$ x $270 \mathrm{~mm}$ with U-shaped D10 arranged around the base material. Fifteen test specimens with the concrete strength set at $21 \mathrm{~N} / \mathrm{mm}^{2}$ and 5 test specimens with the concrete strength set at $60 \mathrm{~N} / \mathrm{mm}^{2}$ were prepared. The compressive strength and the splitting strength of the concrete during the test are shown in Figure 3 with black markers. The concrete strength was within the scope of application of the upper limit $36 \mathrm{~N} / \mathrm{mm}^{2}$ when installing post-installed anchors, and set at $21 \mathrm{~N} / \mathrm{mm}^{2}$ class as the concrete strength generally used in existing buildings and at the upper limit $60 \mathrm{~N} / \mathrm{mm}^{2}$ class of the design standard strength of RC standards.

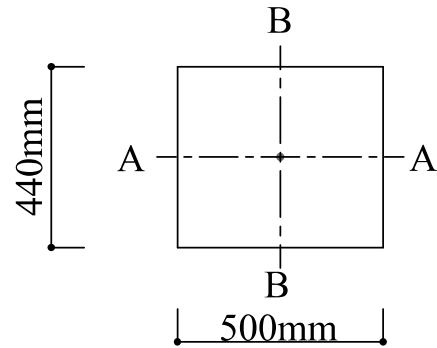

1)View from above

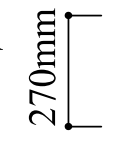

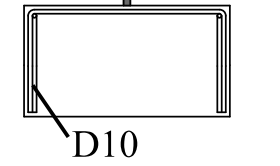

$\downarrow 500 \mathrm{~mm} !$

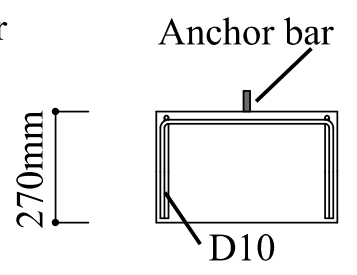

. $440 \mathrm{~mm} !$

Figure 2. Shape of the test specimens

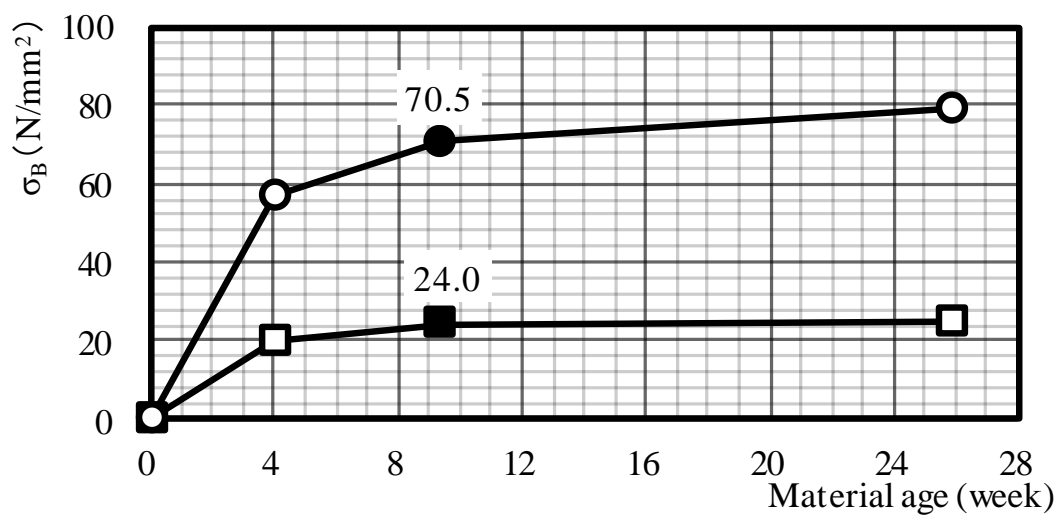

a) Compressive strength

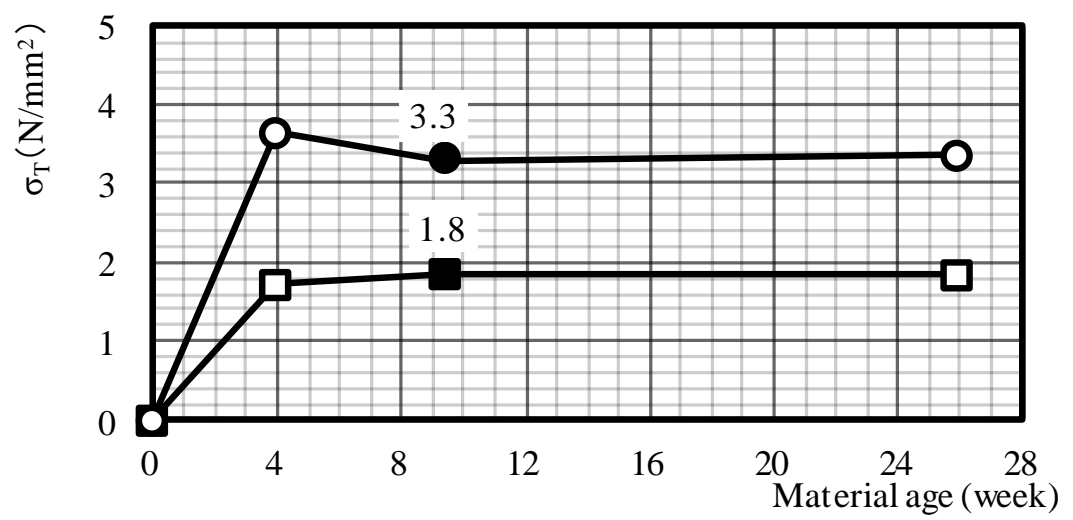

b) Splitting strength

Figure 3. Concrete strength 
The strength of the D10 (SD295A) with a reinforced base material is shown in Figure 4. A $100 \mathrm{~mm} \times 100 \mathrm{~mm}$ grid was drawn on the test specimens and the cracks were observed.

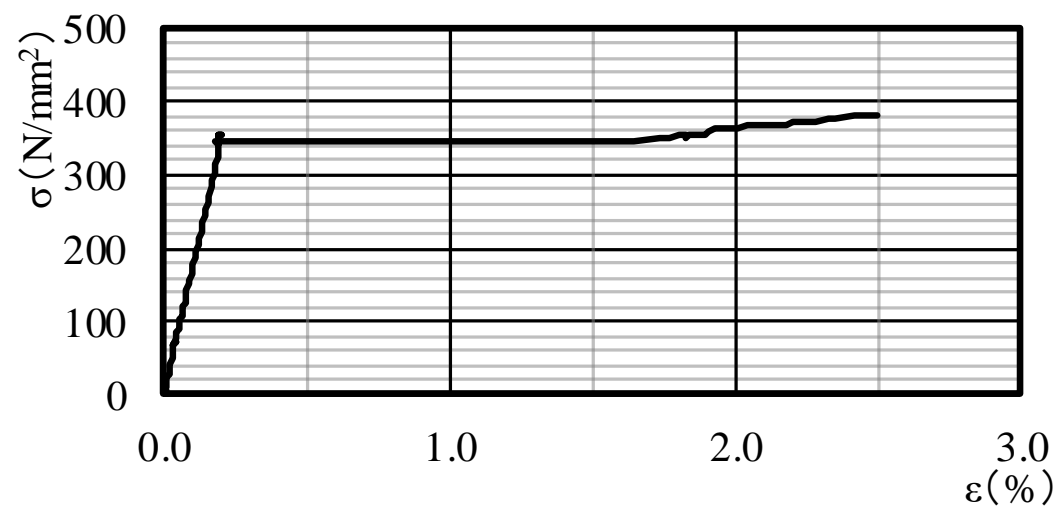

Figure 4. Strength of rebars with reinforced base material D10 (SD295A)

(The strain was measured by a strain gauge)

\subsection{Method for Producing the Flexural Cracks}

The flexural cracks were produced by a three-point bending test. The production method is shown in Figure 5. Two types of size of flexural cracks were set to compare the injection of epoxy resin. Since the acceptable crack width for the degradation of concrete is $0.3 \mathrm{~mm}$ in JASS5, a crack width of $0.4 \mathrm{~mm}$ (hereinafter referred to as small crack) or $0.8 \mathrm{~mm}$ (hereinafter referred to as large crack) when loading so as to be about $0.3 \mathrm{~mm}$ when unloaded, were used as criteria. Unloading was performed after visually confirming with a crack scale that the crack width was larger than the criteria. The width and depth of the flexural cracks are shown in Table 2 . The crack width and the crack depth were measured on three points per test specimen with a microscope and an ultrasonic measuring device, respectively. Compared to during loading, the crack width was narrower after unloading. Moreover, the crack depth was around 50-186 $\mathrm{mm}$ for the small crack test specimens and around $62-204 \mathrm{~mm}$ for the large crack test specimens.

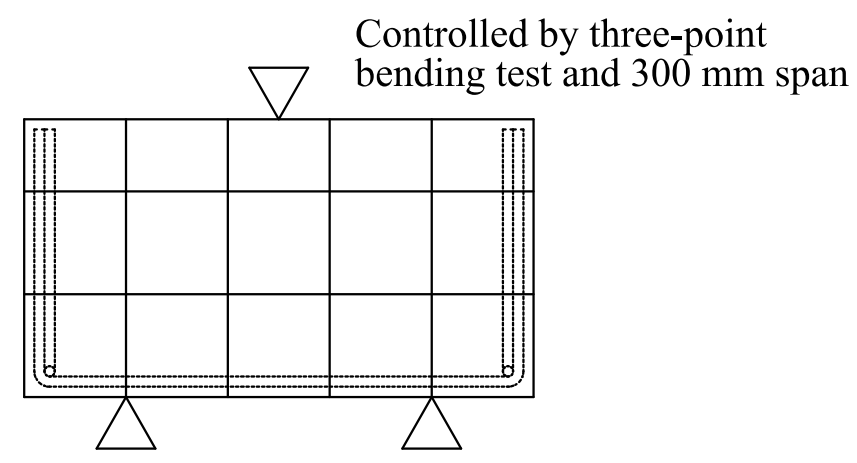

Anchor bar installing surface

Figure 5. Method for producing the flexural cracks 
Table 2. Width and depth of the flexural cracks

\begin{tabular}{|c|c|c|c|c|c|c|}
\hline \multirow[b]{3}{*}{ No. } & \multicolumn{6}{|c|}{ Measured position } \\
\hline & \multicolumn{2}{|c|}{ End part 1} & \multicolumn{2}{|c|}{ Middle } & \multicolumn{2}{|c|}{ End part 2} \\
\hline & $\begin{array}{l}\text { Crack } \\
\text { depth } \\
(\mathrm{mm})\end{array}$ & $\begin{array}{l}\text { Crack } \\
\text { width } \\
(\mathrm{mm})\end{array}$ & $\begin{array}{l}\text { Crack } \\
\text { depth } \\
(\mathrm{mm})\end{array}$ & $\begin{array}{l}\text { Crack } \\
\text { width } \\
(\mathrm{mm})\end{array}$ & $\begin{array}{l}\text { Crack } \\
\text { depth } \\
(\mathrm{mm})\end{array}$ & $\begin{array}{l}\text { Crack } \\
\text { width } \\
(\mathrm{mm})\end{array}$ \\
\hline 1 & 127 & 0.08 & 186 & 0.25 & 158 & 0.20 \\
\hline 2 & 130 & 0.06 & 189 & 0.18 & 136 & 0.10 \\
\hline 3 & 63 & 0.20 & 50 & 0.20 & 61 & 0.22 \\
\hline 4 & 146 & 0.18 & 144 & 0.30 & 165 & 0.22 \\
\hline 5 & 86 & 0.05 & 87 & 0.10 & 68 & 0.08 \\
\hline 6 & 110 & 0.40 & 100 & 0.40 & 156 & 0.16 \\
\hline 7 & 139 & 0.20 & 113 & 0.40 & 149 & 0.30 \\
\hline 8 & 135 & 0.10 & 179 & 0.20 & 132 & 0.18 \\
\hline 9 & 136 & 0.22 & 171 & 0.26 & 156 & 0.04 \\
\hline 10 & 104 & 0.06 & 171 & 0.18 & 141 & 0.28 \\
\hline 11 & 117 & 0.20 & 168 & 0.22 & 130 & 0.18 \\
\hline 12 & - & 0.42 & 172 & 0.25 & 150 & 0.42 \\
\hline 16 & 174 & 0.10 & 156 & 0.10 & 164 & 0.06 \\
\hline 17 & 85 & 0.52 & 62 & 0.54 & 76 & 0.60 \\
\hline 18 & 120 & 0.06 & 155 & 0.20 & 140 & 0.02 \\
\hline 19 & 119 & 0.20 & 204 & 0.28 & 107 & 0.35 \\
\hline
\end{tabular}

- : Unmeasurable

\subsection{Method for Injecting the Epoxy Resin}

The process for repairing the cracks is shown in Figure 6. It was cured by coating with bond along the cracks, to prevent the epoxy resin to leak (Figure 6(a)). Next, penetrating epoxy resin was injected using the automatic low-pressure resin injection method (Figure 6(b)). Finally, the surface was finished by polishing it with a grinder (Figure 6(c)). The properties of the penetrating epoxy resin used here are shown in Table 3, and the properties of the bond are shown in Table 4. Both the penetrating epoxy resin and the bond that were used were the type where a main agent and a curing agent are mixed.

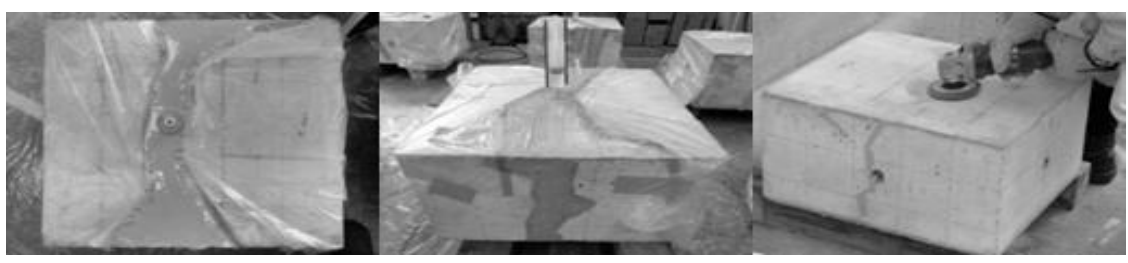
(a) Coating by bond
(b) Epoxy resin
(c) Surface polishing injection 
Figure 6. Process for repairing cracks on the base material

Table 3. Properties of the penetrating epoxy resin

\begin{tabular}{c|c}
\hline $\begin{array}{c}\text { Mixing ratio } \\
\text { (main agent: curing agent) }\end{array}$ & $10: 3$ \\
\hline Density & 1.2 \\
\hline Compressive strength & $123 \mathrm{~N} / \mathrm{mm}^{2}$ \\
\hline Bending strength & $59 \mathrm{~N} / \mathrm{mm}^{2}$ \\
\hline Tensile shear strength & $13 \mathrm{~N} / \mathrm{mm}^{2}$ \\
\hline Adhesive strength & $3.1 \mathrm{~N} / \mathrm{mm}^{2}$ \\
\hline
\end{tabular}

Table 4. Basic properties of the bond

\begin{tabular}{c|l|c}
\hline & Main agent & Curing agent \\
\hline Main components & Epoxy resin & Polythiol, tertiary amine \\
\hline Appearance & White paste & Black paste \\
\hline $\begin{array}{c}\text { Mixing ratio } \\
\text { (main agent: curing } \\
\text { agent) }\end{array}$ & \multicolumn{2}{|c}{$1: 1$} \\
\hline Density & \multicolumn{2}{|c}{$1.50 \pm 0.05$} \\
\hline
\end{tabular}

\subsection{Method for Installing the Anchors}

The boring was made with a drill of $18.0 \mathrm{~mm}$ perforation diameter at the center of the test specimens. The effective embedding lengths were $5 \mathrm{da}, 7 \mathrm{da}$ and $9 \mathrm{da}$ in order to study the differences in failure modes. In order to prevent failures in the anchor bars, the anchor bar material used here was SNB7. The strength of the anchor bars is shown in Figure 7. In the method for installing post-installed anchors, adhesive injectable cartridge types were used. The properties of the adhesive used are shown in Table 5. The adhesive was also the type where a main agent and a curing agent are mixed.

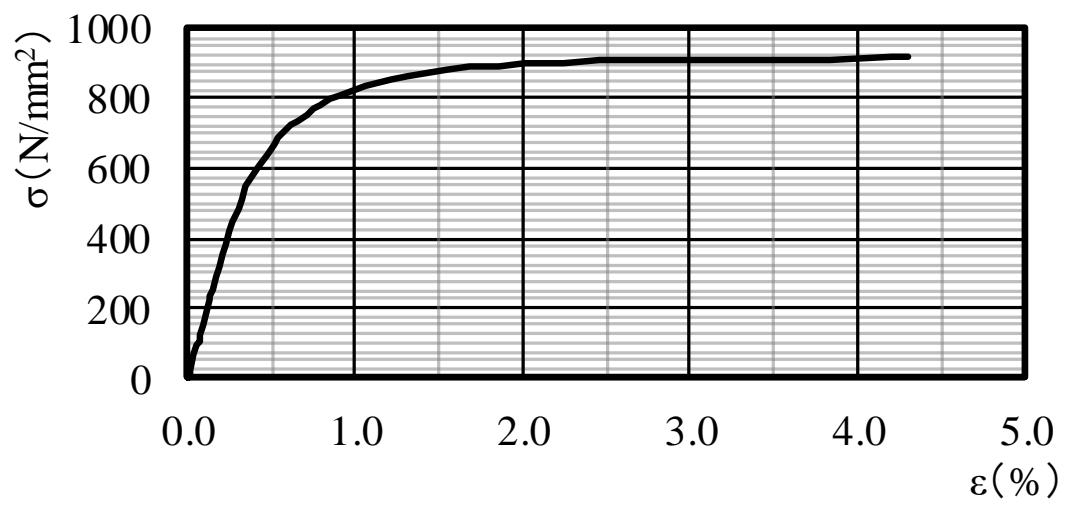

Figure 7. Anchor bar strength M16 (SNB7)

(The strain was measured by a strain gauge) 
Table 5. Properties of the adhesive used in injectable cartridge types

\begin{tabular}{c|c}
\hline Main agent & Non-styrene epoxy acrylate resin \\
\hline Curing agent & BPO (Benzoyl peroxide) \\
\hline
\end{tabular}

\subsection{Method for Pull-Out Testing on Anchor Bars}

The pull-out test on anchor bars was performed by setting the test specimens as shown in Figure 8. The displacements were measured by using two wire-type displacement meters on the position of the anchor bars about $10 \mathrm{~mm}$ from the concrete surface, and the amount of displacement was the average value of the two meters.

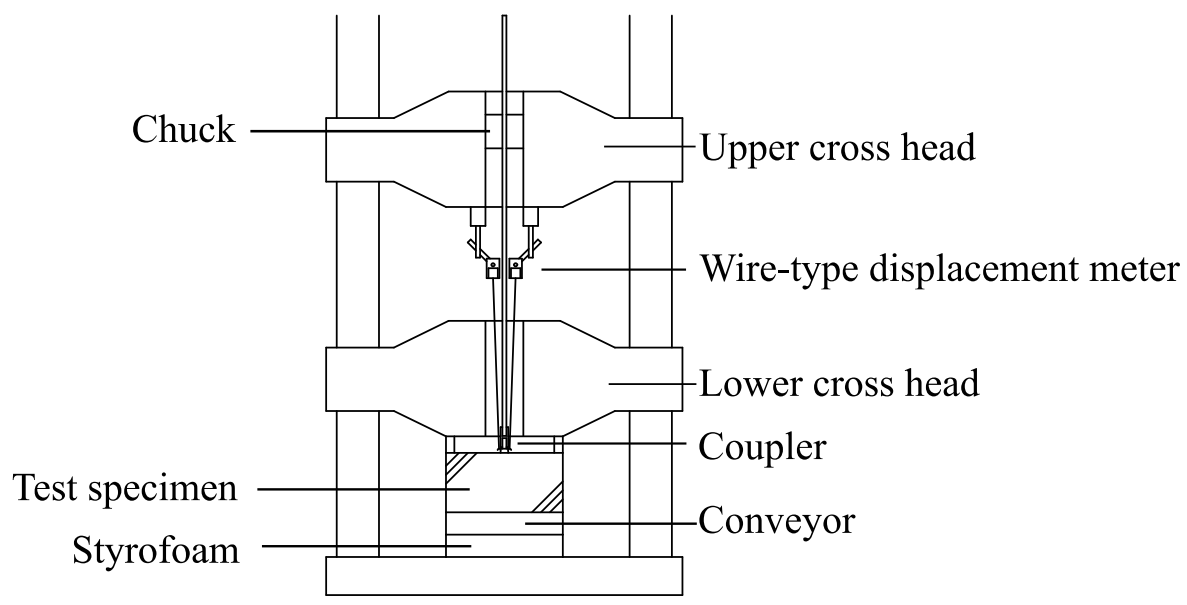

Figure 8. Pull-out testing method

\section{TEST RESULTS}

\subsection{Maximum Load and Failure Modes}

The loads and failure modes from the calculation results and the test results are shown in Table 6, and schematic diagrams of the failure modes are shown in Figure 9. The tensile strength calculation formula of the adhesive post-installed anchors is shown in Formula 1, which is shown in the seismic retrofitting design guideline for existing steel-reinforced concrete structure buildings and its commentary. Here, we review the test specimens without cracks (No. 13, 14, 15, and 20).

First, when the concrete strength is $21 \mathrm{~N} / \mathrm{mm}^{2}$, the calculated value of the cone-type failure is the smallest for the test specimen having an effective embedding length of 5 da. However, since the scope of the effective embedding length is 7 da or more in Formula 1, we assumed that the bond failure mode would precede. Nonetheless, the actual failure mode was a cone-type failure. For the test specimens having an effective embedding length of $7 \mathrm{da}$, we assumed from the calculated value that it would be a cone-type failure. The actual failure mode was a cone-type failure as predicted, and the maximum load was higher than the test specimens with an effective embedding
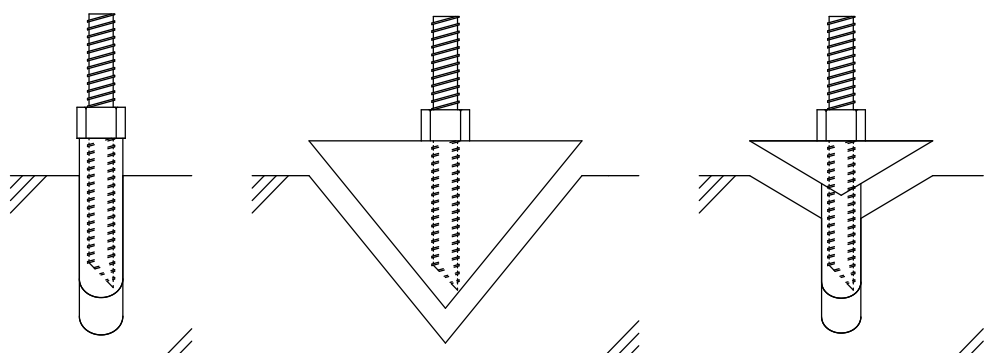

(a) Bond failure
(b) Cone-type failure
(c) Mixed failure

Figure 9. Schematic diagrams of the failure modes

Table 6. List of loads and failure modes

\begin{tabular}{|c|c|c|c|c|}
\hline \multirow[b]{2}{*}{ No. } & \multicolumn{2}{|c|}{ Calculation results } & \multicolumn{2}{|c|}{ Test results } \\
\hline & $\begin{array}{l}\text { Pull-out } \\
\text { resistance } \\
(\mathrm{kN})\end{array}$ & $\begin{array}{l}\text { Predicted failure } \\
\text { mode }\end{array}$ & $\begin{array}{c}\text { Maximum load } \\
(\mathrm{kN})\end{array}$ & $\begin{array}{l}\text { Final failure } \\
\text { mode }\end{array}$ \\
\hline 1 & 40.2 & Bond failure & 50.9 & Cone-type failure \\
\hline 2 & 40.2 & Bond failure & 66.6 & Cone-type failure \\
\hline 3 & 48.5 & Cone-type failure & 59.8 & Cone-type failure \\
\hline 4 & 48.5 & Cone-type failure & 91.5 & Cone-type failure \\
\hline 5 & 72.4 & Cone-type failure & 101.0 & Cone-type failure \\
\hline 6 & 72.4 & Cone-type failure & 106.8 & Cone-type failure \\
\hline 7 & 40.2 & Bond failure & 46.3 & Cone-type failure \\
\hline 8 & 40.2 & Bond failure & 46.9 & Cone-type failure \\
\hline 9 & 48.5 & Cone-type failure & 58.4 & Cone-type failure \\
\hline 10 & 48.5 & Cone-type failure & 59.5 & Cone-type failure \\
\hline 11 & 72.4 & Cone-type failure & 83.1 & Cone-type failure \\
\hline 12 & 72.4 & Cone-type failure & 74.1 & Cone-type failure \\
\hline 13 & 40.2 & Bond failure & 73.1 & Cone-type failure \\
\hline 14 & 48.5 & Cone-type failure & 84.4 & Cone-type failure \\
\hline 15 & 72.4 & Cone-type failure & 123.2 & Cone-type failure \\
\hline 16 & 82.0 & Cone-type failure & 78.9 & Cone-type failure \\
\hline 17 & 82.0 & Cone-type failure & 127.2 & Cone-type failure \\
\hline 18 & 82.0 & Cone-type failure & 76.7 & Mixed failure \\
\hline 19 & 82.0 & Cone-type failure & 86.3 & Cone-type failure \\
\hline 20 & 82.0 & Cone-type failure & 103.7 & Cone-type failure \\
\hline
\end{tabular}

length of $5 \mathrm{da}$. For the test specimens having an effective embedding length of $9 \mathrm{da}$, we assumed that the failure mode would be a cone-type failure. Moreover, we assumed that the pull-out resistance would be the greatest among the test specimens having a concrete strength of $21 \mathrm{~N} / \mathrm{mm}^{2}$, since the effective embedding length was the longest. The test results showed a cone-type failure as predicted, and the maximum load was the biggest among the test specimens having a concrete strength of $21 \mathrm{~N} / \mathrm{mm}^{2}$.

Next, when the concrete strength was $60 \mathrm{~N} / \mathrm{mm}^{2}$, since the concrete strength had 
increased, the maximum load also increased compared to when the concrete strength was $21 \mathrm{~N} / \mathrm{mm}^{2}$. This demonstrated that the longer the effective embedding length is, the maximum load increases, and that the higher the concrete strength is, the maximum load increases.

Formula 1. Tensile strength calculation formula for adhesive post-installed anchors

$T_{a}=\min \left(T_{a 1}, T_{a 2}, T_{a 3}\right)$

$T_{a 1}=\sigma_{y} \cdot a_{0}$

$T_{a 2}=0.23 \sqrt{\sigma_{B}} \cdot A_{C}$

$T_{a 3}=\tau_{a} \cdot \pi \cdot d_{a} \cdot \ell_{e}$

However, $\tau_{a}=10 \sqrt{\sigma_{B} / 21}$

Here,

$T_{a}$ : tensile strength per anchor $(\mathrm{N})$

$T_{a 1}$ : tensile strength per anchor determined by the steel's yield $(\mathrm{N})$

$T_{a 2}$ : tensile strength per anchor

determined by the cone-type failure of the existing concrete skeleton $(\mathrm{N})$

$T_{a 3}$ : tensile strength per anchor

determined by the adherence strength of the adhesive anchor $(\mathrm{N})$

$\sigma_{y}:$ standard yield point of the rebar $\left(\mathrm{N} / \mathrm{mm}^{2}\right)$

$a_{0}$ : effective sectional area in consideration of the screw machining of the joining bar, or nominal cross-section area of the anchor bar $\left(\mathrm{mm}^{2}\right)$

$\sigma_{B}$ : compressive strength of the concrete's existing section $\left(\mathrm{N} / \mathrm{mm}^{2}\right)$

$A_{C}$ : effective horizontal projection area per anchor

to the cone-type failure of the existing skeleton concrete $\left(\mathrm{mm}^{2}\right)$

$\tau_{a}:$ adherence strength to the tensile force of the adhesive anchor $\left(\mathrm{N} / \mathrm{mm}^{2}\right)$

$d_{a}:$ name of the anchor bar $(\mathrm{mm})$

$\ell_{e}$ : effective embedding length of the anchor (mm)

\subsection{Impact of the Repair By Epoxy Resin on the Pull-Out Resistance}

The comparison of pull-out resistance depending on whether the crack is repaired or not is shown in Figure 10 for each effective embedding length. For test specimens where anchor bars were installed without repairing the cracks (marked $\boldsymbol{\Delta}$ and $\Delta$ in the drawing), the pull-out resistance tended to decrease at all effective embedding lengths regardless of the size of the crack, compared to test specimens without cracks (marked $\square$ in the drawing). Relative to the test specimens without cracks, the pull-out resistance of test specimens with small cracks was about $63.3 \%-74.0 \%$, and $60.1 \%-83.2 \%$ for test specimens with large cracks.

On the other hand, for the test specimens where the anchor bars were installed after repairing the cracks (marked $\bullet$ and $\odot$ in the drawing), some of the test specimens with large cracks (No.4 and No.17) had an increased pull-out resistance compared to the test specimens without cracks (marked $\square$ in the drawing). Moreover, when considering 
the size of cracks for those with the cracks repaired, the test specimens with large cracks (marked $\circ$ in the drawing) were found to have an increased pull-out resistance of about $105.7 \%-161.2 \%$ compared to test specimens with small cracks (marked $\bullet$ in the drawing). This may be due to the fact that the penetrating epoxy resin didn't sufficiently reach the cracked part in the test specimens with small cracks and that the repair was insufficient. In test specimens with large cracks, the penetrating epoxy resin

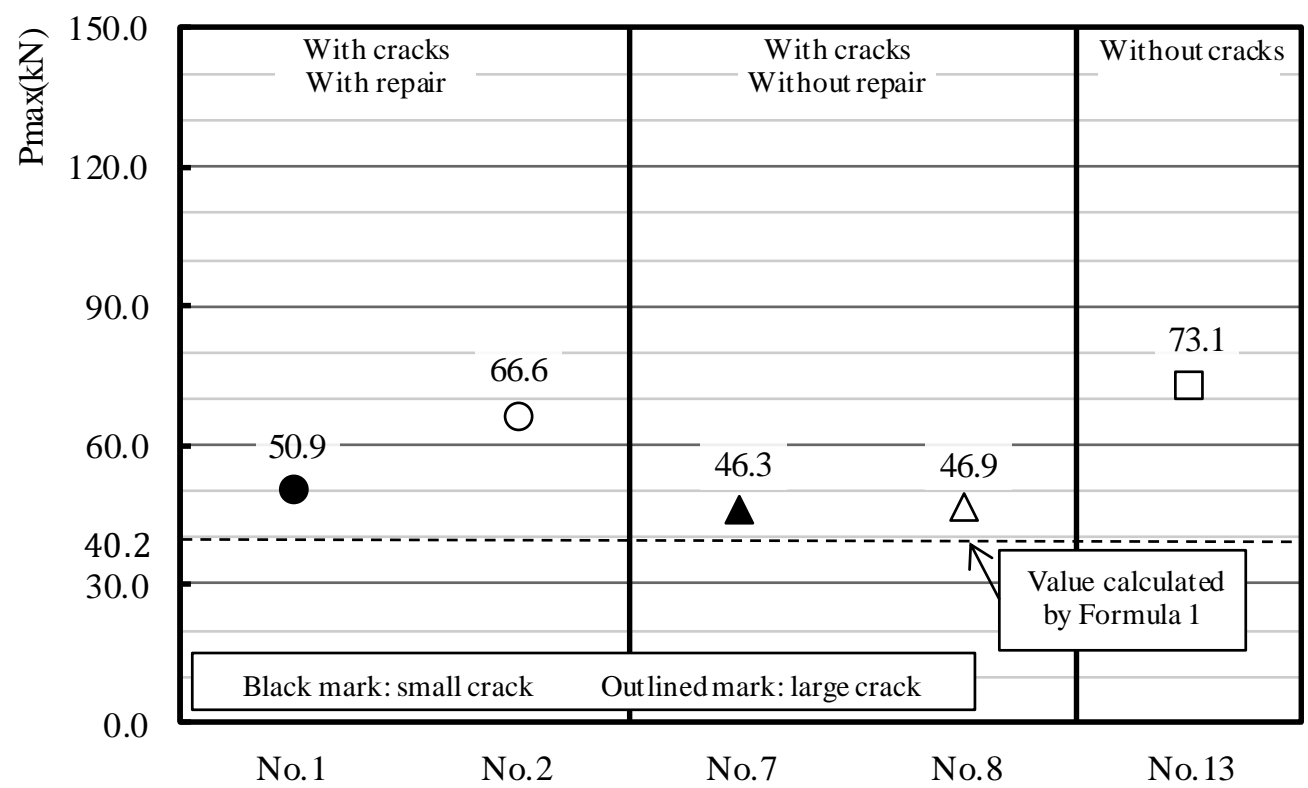

a) Effective embedding length $5 \mathrm{da}$ (concrete strength $21 \mathrm{~N} / \mathrm{mm}^{2}$ )

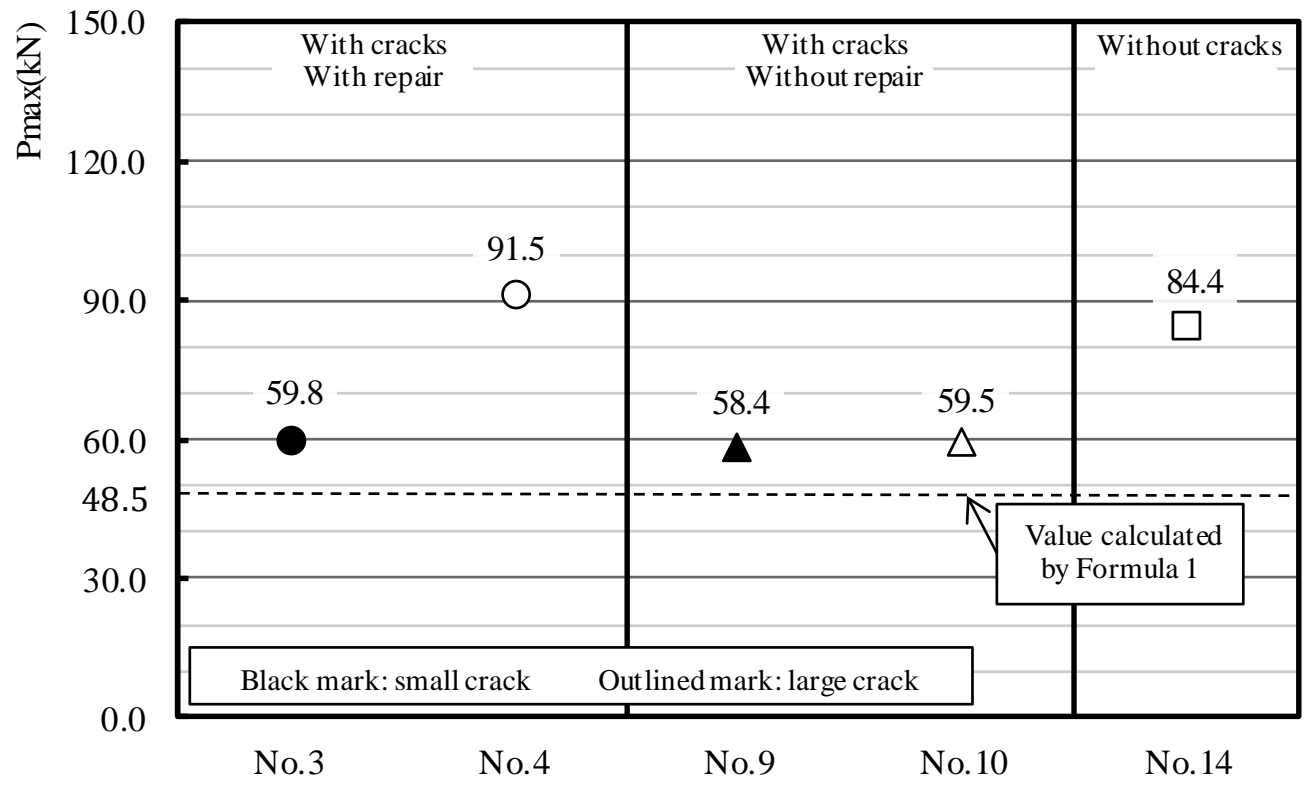

b) Effective embedding length $7 \mathrm{da}$ (concrete strength $21 \mathrm{~N} / \mathrm{mm}^{2}$ ) Figure 10. Pull-out resistance for each effective embedding length 


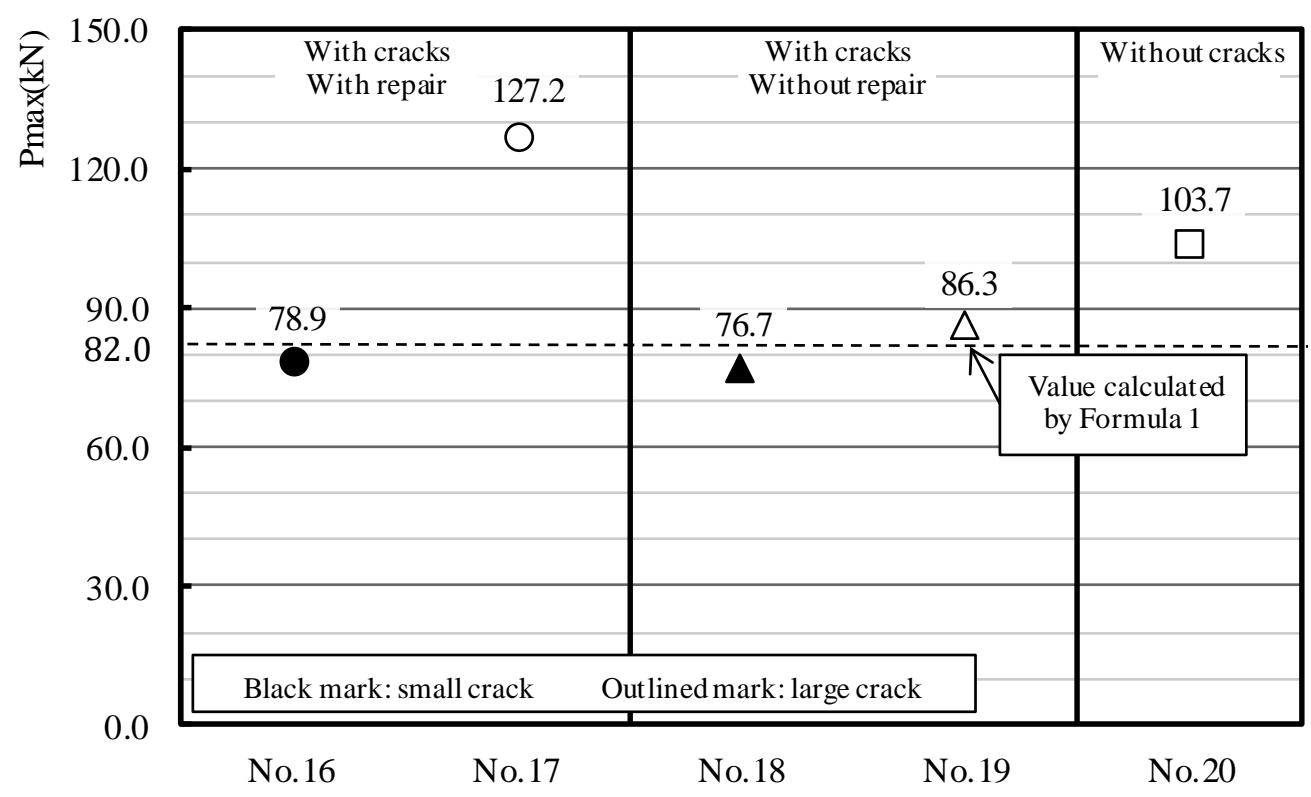

c) Effective embedding length 7 da (concrete strength $60 \mathrm{~N} / \mathrm{mm}^{2}$ )

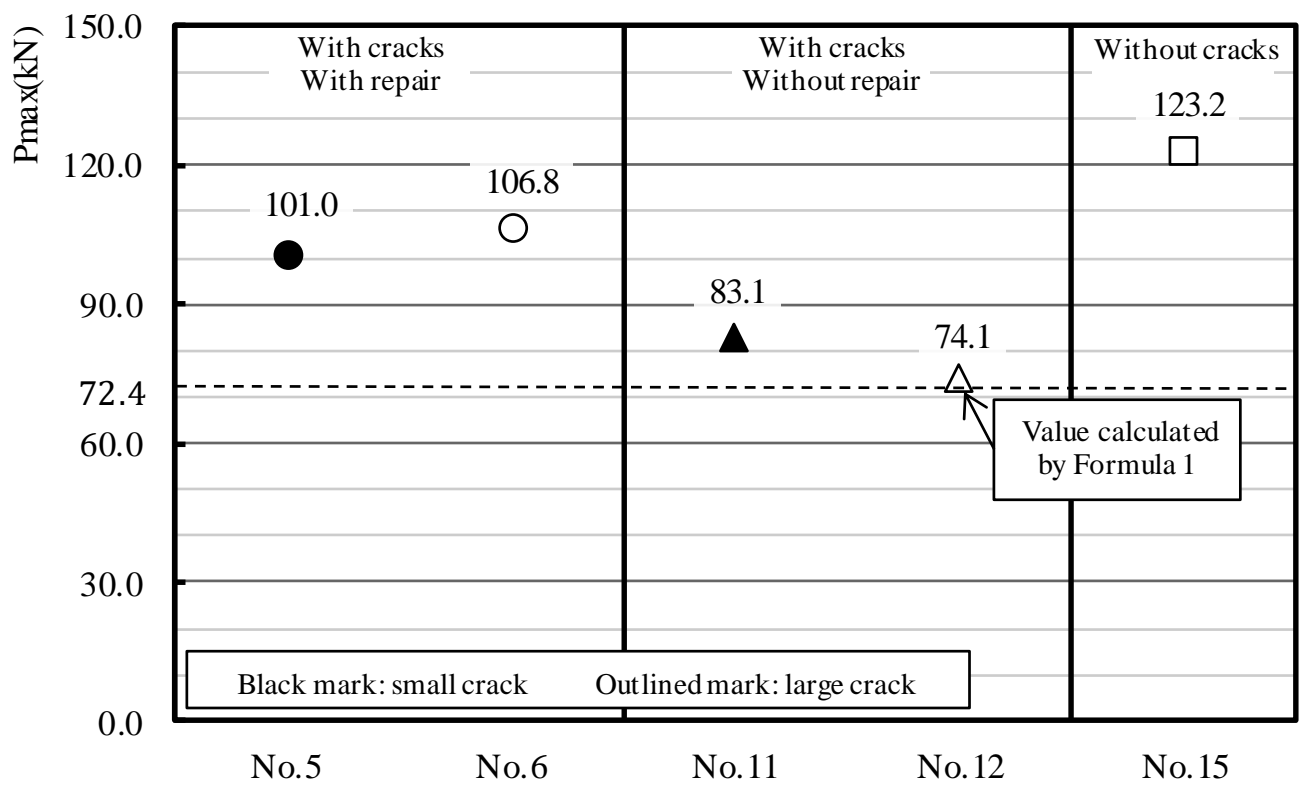

d) Effective embedding length 9 da (concrete strength $21 \mathrm{~N} / \mathrm{mm}^{2}$ ) Figure 10. Pull-out resistance for each effective embedding length 
could sufficiently penetrate the cracks and became integrated in the cracked concrete, which may have led to have cases where the pull-out resistance exceeded that of test specimens without cracks.

As a result, the effectiveness of installing post-installed anchors after repairing the cracks was significant for the test specimens with large cracks, but for test specimens with small cracks, in some cases, the repair by epoxy resin was difficult, and the pullout resistance was about the same as that of without repair.

\section{SUMMARY}

From the study of the pull-out resistance of post-installed anchors, repaired using penetrating epoxy resin in the base material cracks, the following findings were obtained within the range of this pull-out test.

1) With equal effective embedding length $(7 \mathrm{da})$, the pull-out resistance increased when the concrete strength was $60 \mathrm{~N} / \mathrm{mm}^{2}$ compared to $21 \mathrm{~N} / \mathrm{mm}^{2}$.

2) Compared to test specimens without cracks, the test specimens with cracks but without repair of the cracks tended to have a decreased pull-out resistance.

3) In the test specimens with cracks repaired by epoxy resin, the test specimens with large cracks were found to have an increased pull-out resistance compared to test specimens with small cracks, and in some cases, were also found to have an increased pull-out resistance compared to test specimens without cracks.

This study has demonstrated that the pull-out resistance increases when installing post-installed anchors after repairing the cracks for the test specimens with large cracks, but we would like to further investigate the approximate crack width for which we can expect sufficient penetration of the penetrating epoxy resin.

\section{ACKNOWLEDGEMENTS}

This work was supported by the Japan Construction Anchor Association, including Masayuki Ogaki. Kiyoshi Ito of Kajima Road Co., Ltd. provided us technical guidance regarding the usage of penetrating epoxy resin adhesives. We hereby express our gratitude.

\section{REFERENCES}

Hideo ARAKI and Seiya IZAKI (2012). "Seismic Performance of Damaged Low Strength Concrete Column Repaired by Epoxy Resin Injection", Architectural Institute of Japan, Journal of Technology and Design, Vol. 18, No.38, pp.181-186, Feb., 2012 
K. Aoki, H. Nishida, H. Maeda and R. Ishihara (2016). "Testing and Behavior of Postinstalled Anchors in Cracked Concrete", Concrete Journal, Vol.54, No.2, pp.170-175, Feb. 2016

Architectural Institute of Japan (2010), AIJ Standard for Structural Calculation of Reinforced Concrete Structures (RC Standards)

Architectural Institute of Japan (2015), Japanese Architectural Standard Specification JASS5 Reinforced Concrete Work 